\title{
Research Article \\ The Correlation between Dental Stages and Skeletal Maturity Stages
}

\author{
Ayah Jourieh, ${ }^{1}$ Haris Khan, ${ }^{2}$ Samer Mheissen $\left(\mathbb{D},{ }^{3}\right.$ Muhammad Assali, ${ }^{4}$ \\ and Mohammad Khursheed Alam ${ }^{5}{ }^{5}$ \\ ${ }^{1}$ Aleppo Specialized Orthodontic Center, Aleppo, Syria \\ ${ }^{2}$ CMH Institute of Dentistry Lahore, National University of Medical Sciences, Punjab, Pakistan \\ ${ }^{3}$ Syrian Board in Orthodontics, Orthodontic Department, Syrian Ministry of Health, Private Practice, Damascus, Syria \\ ${ }^{4}$ Aleppo Specialized Center, Aleppo, Syria \\ ${ }^{5}$ Orthodontic Division, College of Dentistry, Jouf University, Saudi Arabia
}

Correspondence should be addressed to Samer Mheissen; mheissen@yahoo.com

Received 16 March 2021; Revised 24 May 2021; Accepted 28 May 2021; Published 10 June 2021

Academic Editor: Vincenzo Grassia

Copyright (C) 2021 Ayah Jourieh et al. This is an open access article distributed under the Creative Commons Attribution License, which permits unrestricted use, distribution, and reproduction in any medium, provided the original work is properly cited.

Introduction. The determination of skeletal maturity stages is very important in orthodontic treatment planning, especially skeletal discrepancies in growing individuals. A hand-wrist radiograph is considered the most accurate approach for skeletal maturity detection. Dental calcification stages have been suggested as an alternative diagnostic method to decrease radiation exposure. The recent study is aimed at detecting the efficacy of dental calcification stages in assessing skeletal maturity during the prepubertal and pubertal growth periods. Methods. Patients' records were collected from the Aleppo Orthodontic Center. Dental maturity stages were assessed from a panoramic radiograph using the Demirjian method, while skeletal maturity stages were determined using the Björk method. Four permanent left mandibular teeth were included (canine, 1st premolar, 2nd premolar, and 2nd molar) for the study. Results. From 517 records, 295 records (145 males and 150 females) were included. The Spearman rank-order correlation coefficients between skeletal maturation and dental maturation were strong and statistically significant (ranging from 0.789 to 0.835$)$. The highest correlation was between skeletal stages and the second molar $(r=0.829$ and 0.88 in males and females, respectively). Receiver operating characteristic (ROC ) curve suggested a high validity of the sum of dental stages for the four teeth in identifying MP3= stage (sensitivity was 70\%, specificity was $92.77 \%$, and ROC area was 0.81 ) but not for MP3cap (sensitivity was $50.85 \%$, specificity was $81.36 \%$, and ROC area was 0.66 ). Conclusions. The correlation between the skeletal maturity stages and the dental calcification stages was high. The orthodontist can use the dental stages as a definite diagnostic tool for prepubertal growth period.

\section{Introduction}

The timing of pubertal growth and its duration varies between genders and different types of malocclusions [1]. Also, most patients seeking orthodontic treatment are young and secular trends have been reported for growth over time, and children are growing much faster and maturing earlier [2]. So, orthodontists should have a good knowledge of assessing skeletal maturation of growing patients as it can directly or indirectly affect the diagnosis, planning, outcome, and retention protocol in orthodontic treatment $[3,4]$. Correct timing of orthodontic treatment also helps to achieve more rapid tooth movement [5].

The children's growth status can be accessed by different indicators such as chronological age, secondary sexual characteristics, growth curves, skeletal age, and dental age [3]. Chronological age is not adequate since hereditary, ecological, nutritional, and hormonal factors can affect it [6]. Ethics, local traditions, gender, and racial dysmorphism limit the use of secondary sexual characteristics for growth assessment in orthodontics [7]. Growth curves are also less predictable due to the secular trends for increased height with time [2]. 
In the skeletal age, the most reliable method that has traditionally been used is hand and wrist radiographs [8]. But using this $\mathrm{X}$-ray just for age assessment increases the radiation exposure of the patient. So, over a period of time, different radiological methods are proposed to avoid exposure to additional radiations. Cervical vertebra maturation is usually advised in contemporary orthodontics for estimation of skeletal age, but studies $[9,10]$ have questioned its reliability and reproducibility over time.

Dental age can be used to estimate skeletal age because it is less influenced by nutritional and endocrinal factors and it does not add any extra radiation exposure [11]. Dental age can be evaluated in children and teenagers either by the time of teeth emergence in the mouth or by teeth mineralization stages. Mineralization stages of teeth are considered more accurate [12], especially the method proposed by Demirjian et al. [13], as it takes the ratios of root length relative to crown height, instead of absolute length, so the flaws in the inaccurate projections of developing teeth will not affect the quality of the evaluation [14].

The dental literature has no scarcity for research related to correlation between dental calcification stages and skeletal maturation stages. But these studies have the following shortcomings: (a) lack of sample size calculation [14-21], (b) very small sample size [17], (c) evaluation of maxillary teeth while they are superimposed by other structures [22], (d) wide age range (patient age greater than 16 years) $[19,20]$, and (e) inclusion of teeth at the age where root formation either has not yet started or has already been completed $[14,18-$ 20]. A systematic review and meta-analysis [23] also pointed out methodology errors and high heterogeneity in the published on this topic research. The aim of this paper is to do a well-structured study to evaluate the relations between the dental calcification stages measured on panoramic radiographs and five skeletal maturity stages of bones of the hand-wrist region.

\section{Materials and Methods}

Due to the retrospective nature of the recent study, the ethical committee raised no ethical concerns.

The data were collected retrospectively from 517 records from the Aleppo Specialized Orthodontic Center in September 2019. The first author evaluated the patients' records to match the inclusion criteria: Healthy Syrian children with fully erupted incisors and first permanent molars, good quality panoramic image, and available hand and wrist radiographs. Subjects with dental anomalies, premature extractions of primary molars or canines, trauma or surgery to facial structures or hand and wrist, syndromes, missing left quadrant mandibular teeth, and systematic disease were excluded from the study.

Sample size calculation was done using G*Power software version 3.1 by correlation test with a study power of $90 \%$ for five skeletal groups, and the significance level was set at $5 \%$ with an effect size of 0.4 . The required sample size was 250 .

In this study, the hand and wrist skeletal maturity stages were taken as a gold standard and were evaluated using the method described by Björk and Helm and Grave and Brown $[24,25]$. To facilitate the assessment with clear discrimination between the stages, only 5 out of 9 skeletal maturity stages $(\mathrm{MP} 3=, \mathrm{R}=, \mathrm{S}, \mathrm{MP} 3 \mathrm{cap}$, and $\mathrm{DP} 3 \mathrm{u})$ were used. Each skeletal stage of the hand and wrist represents a specific period in the pubertal growth spurt curve. The MP3= and the $\mathrm{R}=$ stages represent the start of the pubertal growth spurt, the $S$ and the MP3cap stages represent a period of very rapid growth velocity, and the DP3u stage represents the period of decelerating growth rate in both genders [26].

Dental maturity was assessed on the panoramic radiograph using Demirjian et al. [13] method. Four permanent mandibular teeth were included (canine, 1st premolar, 2nd premolar, and 2 nd molar) from the left side. These teeth were selected because the closure of the apices of the incisors and first molars had already occurred. The third molars were excluded because of uncertainty regarding the formation and the poor correlation with skeletal maturity [27]. Maxillary teeth were also excluded as their roots overlap with the calcified structures in this area, such as the zygomatic arch or the maxillary sinus or zygomatic process, which makes interpretation difficult [18]. Based on the apex closure [13], the teeth were rated accordingly from stage $A$ to $H$.

2.1. Statistical Analysis. The data were analyzed using Stata SE 15. Spearman's rank-order correlation coefficient was used to assess the correlations between the skeletal and dental maturity stages. The results were significant if the $P$ value was less than or equal to 0.05 . Also, the correlations were considered strong and positive if the $r$ value is more than 0.7 , moderate if the $r$ value is from 0.3 to 0.7 , and weak if the $r$ value is less than 0.3. For using orthopantomograph (OPG), as a diagnostic tool for skeletal stages the dental stages were coded by numbers (A: 1; B: 2; C: 3; D: 4; E: 5; F: 6; G: 7; and H: 8) using a receiver operating characteristic curve (ROC) to figure out the sensitivity and the specificity of the sum of the four stages. The sensitivity and specificity were used to evaluate the four permanent teeth stages' effectiveness in the assessment of the skeletal maturity stages of the prepubertal and pubertal growth period. One hundred records were reassessed after one month by the same examiner blindly, and Kappa analysis was used to define the intraexaminer reliability. Also, the third author randomly chose 30 cases and reassessed them for accuracy with no difference between the two authors.

\section{Results}

Out of 517 patients' records, 295 patients met the inclusion criteria with a mean age of 12.5 years (range 9-14 years) (Figure 1). The records were assessed with high intraexaminer reliability of $94 \%$ (Kappa analysis). According to skeletal maturity stages and gender, the distribution of the sample is presented in Table 1. Spearman rank-order correlation coefficients between the skeletal maturity indicators of the hand and wrist bones and the calcification stages of the four teeth are shown in Table 2.

The correlation was statistically significant and ranged from 0.789 to 0.835 ( 0.79 to 0.829 in males and 0.79 to 0.88 


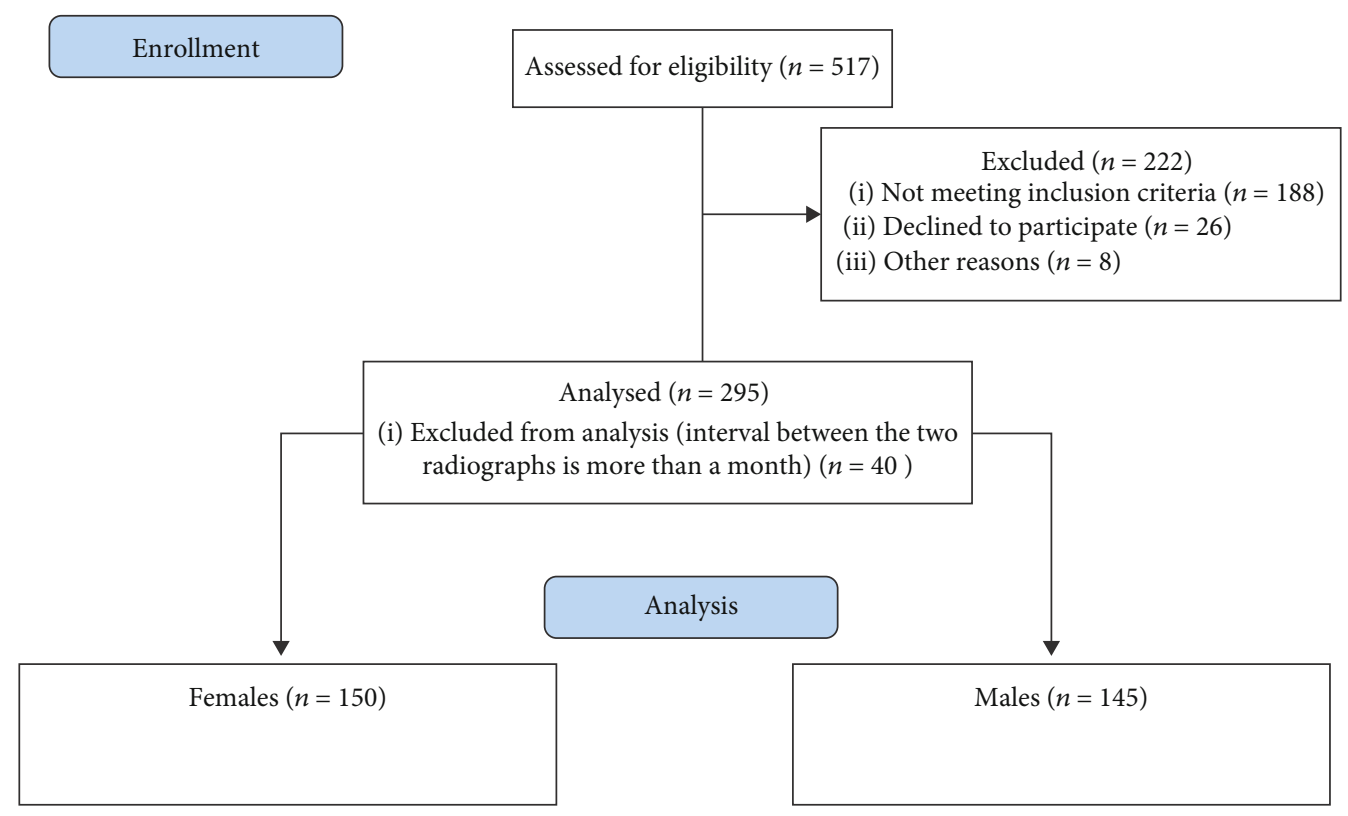

Figure 1: Flow diagram.

TABLE 1: Distribution of the sample according to skeletal maturity stages and gender.

\begin{tabular}{lcccccc}
\hline \multirow{2}{*}{ Gender } & \multicolumn{6}{c}{ Skeletal maturation stages } \\
& MP3 $=$ & R= & S stage & MP3cap & Dp3u & Total \\
\hline \multirow{2}{*}{ Female } & 30 & 30 & 30 & 30 & 30 & 150 \\
& $10.16 \%$ & $10.16 \%$ & $10.16 \%$ & $10.16 \%$ & $10.16 \%$ & $50.84 \%$ \\
Male & 30 & 30 & 30 & 30 & 25 & 145 \\
& $10.16 \%$ & $10.16 \%$ & $10.16 \%$ & $10.16 \%$ & $8.47 \%$ & $49.15 \%$ \\
Total & 60 & 60 & 60 & 60 & 55 & 295 \\
& $20.33 \%$ & $20.33 \%$ & $20.33 \%$ & $20.33 \%$ & $18.64 \%$ & $100.00 \%$ \\
\hline
\end{tabular}

TABLE 2: Correlation of skeletal maturity indicators and calcification stages of teeth.

\begin{tabular}{lcccc}
\hline Gender & Canine & $\begin{array}{c}1 \text { st } \\
\text { premolar }\end{array}$ & $\begin{array}{c}\text { 2nd } \\
\text { premolar }\end{array}$ & $\begin{array}{c}\text { 2nd } \\
\text { molar }\end{array}$ \\
\hline $\begin{array}{l}\text { Male skeletal stage } \\
r\end{array}$ & $0.7997^{*}$ & $0.7931^{*}$ & $0.8133^{*}$ & $0.8293^{*}$ \\
$\begin{array}{l}\text { Female skeletal } \\
\text { stage } r\end{array}$ & $0.7902^{*}$ & $0.8123^{*}$ & $0.8174^{*}$ & $0.8802^{*}$ \\
$\begin{array}{l}\text { Total skeletal stage } \\
r\end{array}$ & $0.7912^{*}$ & $0.7899^{*}$ & $0.7951^{*}$ & $0.8355^{*}$ \\
\hline
\end{tabular}

$r$ : correlation coefficient indicates a strong positive correlation. ${ }^{*} P$ value is less than 0.001 .

in females), indicating strong positive correlation. The highest to the lowest correlation was the 2 nd molar, the 2 nd premolar, the canine, and the 1st premolar in males; while, it was the 2nd molar, the 2nd premolar, the 1st premolar, then the canine in females. The 2nd molar showed the highest correlation both in males $(r=0.829, P<0.001)$ and females ( $r=0.88, P<0.001)$. The 1 st premolar showed the lowest correlation $(r=0.789, P<0.001)$ in both genders.
The correlations between the individual teeth' calcification stages and the stages of skeletal maturity are shown in Figures 2(a)-2(d).

At the MP3= stage of skeletal maturation, the canine stage $\mathrm{F}$ was seen in $90 \%$ of the sample, while in the R stage, the 2 nd premolar stage $\mathrm{F}$ was most frequent (73. 33\%). In the $\mathrm{S}$ stage, the second molar stage $\mathrm{F}$ was predominant in females $(70 \%)$, while the second molar stage $G$ was predominant in males (63.33\%). In the MP3cap stage, the second molar stage $G$ has the most frequency of $76.66 \%$ in females and $86.66 \%$ in males.

There was a high sensitivity of $70 \%$, specificity $92 \%$, and ROC area of 0.81 for using the sum of the dental stages for the four index teeth in predicting the MP3= stage when this sum was between 20 and 24. The sensitivity was $50.85 \%$, and the specificity was $81.36 \%$ for using the sum of the dental stages for the four index teeth in predicting the MP3cap stage when this sum was between 28 and 30 with a ROC area of 0.66 (Figure 3).

\section{Discussion}

The recent study found a strong correlation between the dental and skeletal maturity stages which is in agreement with previous studies $[14,20,27-33]$. In contrast, Sahin [34] found an insufficient correlation between dental and skeletal maturity (0.47-0.55 in males and 0.58-0.64 in females). The reason for the difference between our findings and Sahin's findings [34] might be because they have included maxillary teeth in their study and these teeth roots overlap with neighboring structures, thus decreasing the validity of their method.

The strongest correlation in our findings was between the 2nd molar's stages and the skeletal age $(r=0.8355, P<0.001)$. These findings are in agreement with other studies from different ethnicities $[20,28,29,35,36]$. The advantage of using the 


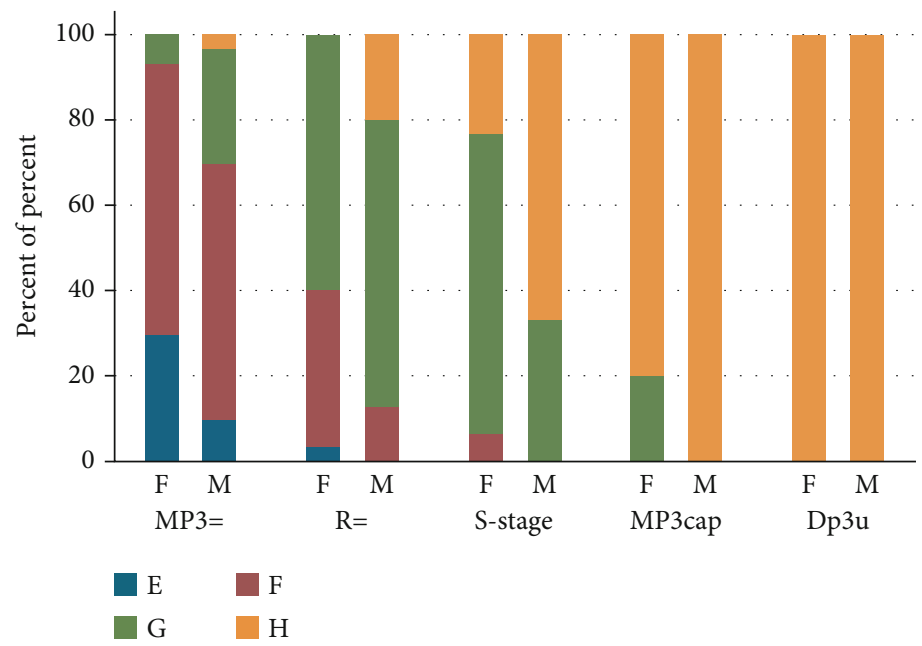

(a) Distribution of the skeletal maturity stages and the calcification stages in the 2nd molar in both males and females

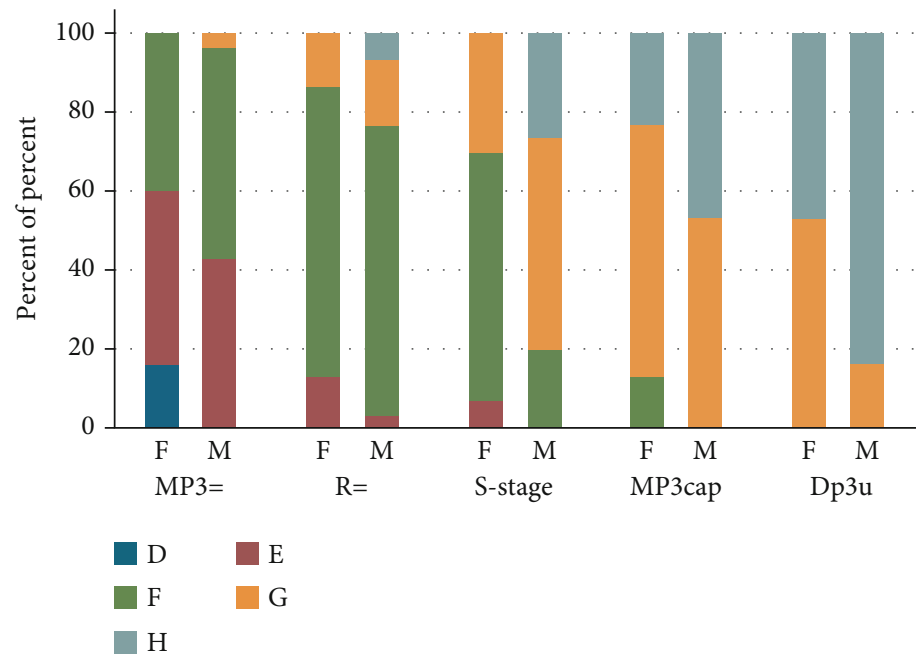

(b) Distribution of the skeletal maturity stages and the calcification stages in the 2nd premolar in both males and females

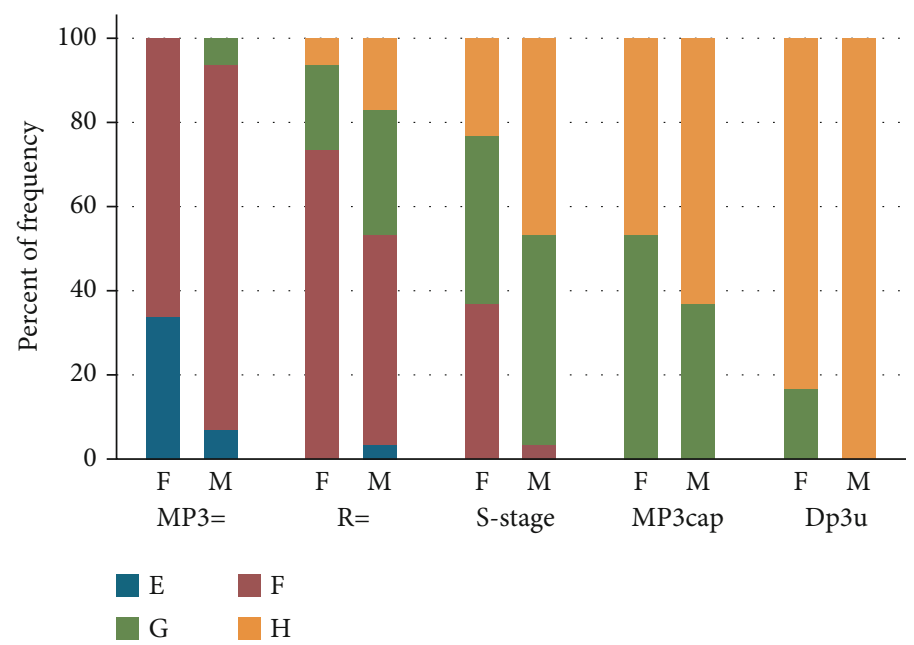

(c) Distribution of the skeletal maturity stages and the calcification stages in the 1st premolar in both males and females

FIgURE 2: Continued. 


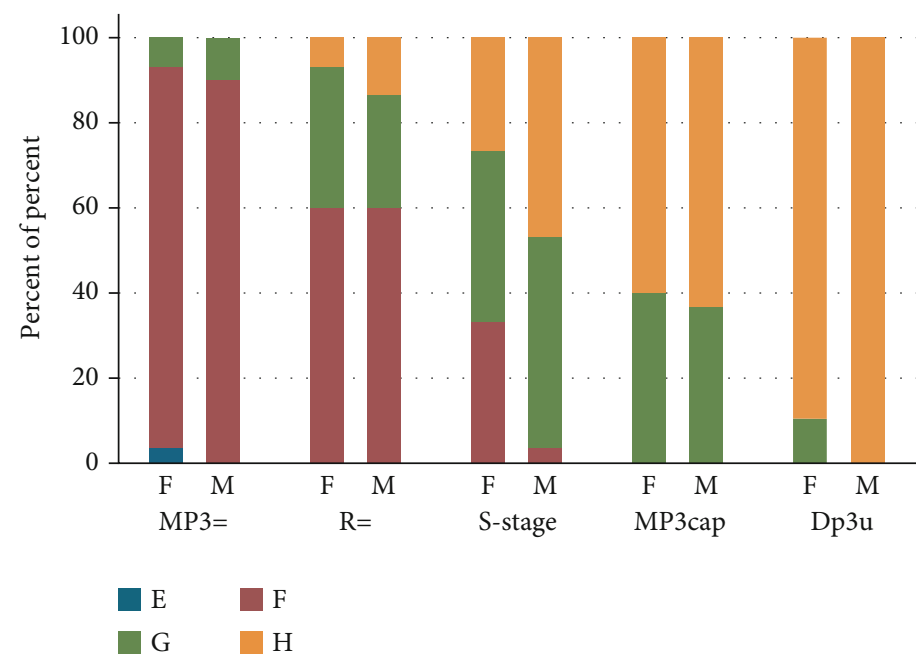

(d) Distribution of the skeletal maturity stages and the calcification stages in the canine in both males and females

Figure 2

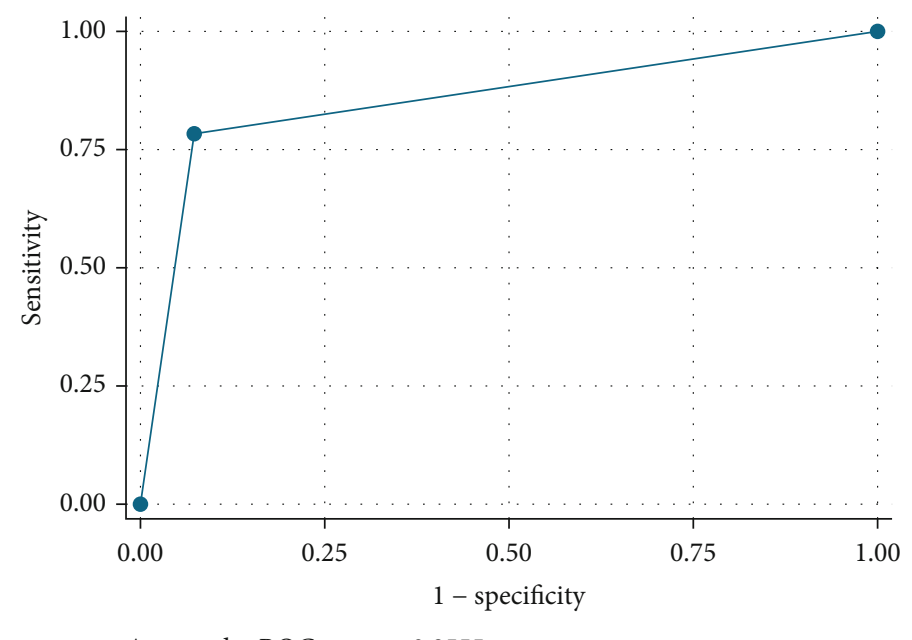

Area under ROC curve $=0.8555$

FIgURE 3: Receiver operating characteristic (ROC) curve representing a good sensitivity for the dental stages as diagnostic tool in the prepubertal period.

2nd molar is that it continues to mature over a longer period of time, and its apices may not close up to 16 years of age in normal children [29].

In contrast, some studies [27, 31, 37] have suggested a strong correlation between the mineralization of mandibular canine and the skeletal maturity indicators, while Krailassiri et al. [14] found that the 2 nd premolars showed the highest correlation ( $r=0.66$ and 0.69 ) for males and females, respectively. The reason for these differences between our findings and other studies $[14,27,31,37]$ might be that the age range was very wide in those studies, exceeding the growth spurt period.

Many studies differentiated between males and females when evaluating the correlation between skeletal maturation and dental calcification stages [14, 28, 34]. Therefore, we studied these correlations separately for males and females. The present study found that teeth developmental patterns were more advanced in males at the same skeletal maturity stage compared to females. Males had a trend toward an acceleration in tooth mineralization. This result was similar to Chertkow's findings [27]. Contrary to our results, two studies $[38,39]$ found that the correlation has no statistically significant gender differences. These studies $[38,39]$ used the open apices approach described by Cameriere et al. [40], which is different from Demirjian et al.'s [41] method used in the present study.

A distinctive dental maturity pattern of specific teeth was noticed in the present study in each of the five skeletal stages. These observations corresponded with the findings of several studies, but with a different rate. The recent study found consistency between the canine stage $\mathrm{F}$ and the second molar stage E that coincided with the MP3= stage. Similar findings were reported by previous studies $[14,28,30,31]$. Also, the second premolar stage $\mathrm{F}$ coincided with the $\mathrm{R}$ stage, while the second molar stage G coincided with the MP3cap stage $[14,29,30]$. However, the present study found that the root 
formations of the canines and the first premolars were completed in the MP3cap stage in most male subjects, which agrees with the available literature [14, 28], while at the DP3u stage, most of the canines and first premolars were in stage $\mathrm{H}$ in females, which agrees with the available literature [38].

For using OPG as a diagnostic tool for skeletal age, if the four teeth dental stages were $\mathrm{E}$ or $\mathrm{F}$, then this indicates the MP3= with high sensitivity and specificity. But if the four teeth dental stages were $G$ or at least two of them were G, then this indicates the MP3cap stage with a fair sensitivity and with good specificity. As the sensitivity was $50.85 \%$ for the MP3cap stage, so the certainty of diagnosing this stage was low with dental maturation stages. Similar conclusions were made by other studies [33, 42, 43].

Though the study design was retrospective, the recent study has a proper sample size with rigor inclusion criteria and used a valid method to assess the skeletal and dental stages. However, longitudinal growth studies are recommended to precisely predict skeletal age from orthopantomogram images.

\section{Conclusion}

The correlation between dental and skeletal stages was strong. Canine F stage coincides with the MP3= stage, while the second molar G stage coincides with the MP3cap stage. The dental maturation stages can be used as an indicator for skeletal maturation with a high diagnostic value for the prepubertal growth period.

\section{Data Availability}

The corresponding author will be sharing data underlying this article on reasonable request.

\section{Conflicts of Interest}

The authors declare that they have no conflicts of interest.

\section{References}

[1] W. Jeelani, M. Fida, and A. Shaikh, "The duration of pubertal growth peak among three skeletal classes," Dental Press Journal of Orthodontics, vol. 21, no. 5, pp. 67-74, 2016.

[2] P. Marques-Vidal, G. Madeleine, S. Romain, A. Gabriel, and P. Bovet, "Secular trends in height and weight among children and adolescents of the Seychelles, 1956-2006," BMC Public Health, vol. 8, no. 1, p. 166, 2008.

[3] G. Songra, T. K. Mittal, J. C. Williams, J. Puryer, J. R. Sandy, and A. J. Ireland, "Assessment of growth in orthodontics," Orthodontic Update, vol. 10, no. 1, pp. 16-23, 2017.

[4] V. Grassia, F. d'Apuzzo, A. Jamilian, F. Femiano, L. Favero, and L. Perillo, "Comparison between rapid and mixed maxillary expansion through an assessment of arch changes on dental casts," Progress in Orthodontics, vol. 16, no. 1, p. 20, 2015.

[5] A. J. Ireland, G. Songra, M. Clover, N. E. Atack, M. Sherriff, and J. R. Sandy, "Effect of gender and Frankfort mandibular plane angle on orthodontic space closure: a randomized con- trolled trial," Orthodontics \& Craniofacial Research, vol. 19, no. 2, pp. 74-82, 2016.

[6] M. T. de Souza Araujo, A. de Alcantara Cury-Saramago, and A. F. J. da Motta, "Clinical and radiographic guidelines to predict pubertal growth spurt," Journal of Orthodontics, vol. 16, no. 5, pp. 98-103, 2011.

[7] E. J. Susman, R. M. Houts, L. Steinberg et al., "Longitudinal development of secondary sexual characteristics in girls and boys between ages 91/2 and 151/2 years," Archives of Pediatrics \& Adolescent Medicine, vol. 164, no. 2, pp. 166-173, 2010.

[8] H. A. Hashim, H. Mansoor, and M. H. H. Mohamed, "Assessment of skeletal age using hand-wrist radiographs following Bjork system," Journal of International Society of Preventive and Community Dentistry, vol. 8, no. 6, pp. 482-487, 2018.

[9] A. Predko-Engel, M. Kaminek, K. Langova, P. Kowalski, and P. S. Fudalej, "Reliability of the cervical vertebrae maturation (CVM) method," Bratislavské Lekárske Listy, vol. 116, no. 4, pp. 222-226, 2015.

[10] D. B. Gabriel, K. A. Southard, F. Qian, S. D. Marshall, R. G. Franciscus, and T. E. Southard, "Cervical vertebrae maturation method: poor reproducibility," American Journal of Orthodontics and Dentofacial Orthopedics, vol. 136, no. 4, pp. 478.e1478.e7, 2009.

[11] C. J. McKenna, H. James, J. A. Taylor, and G. C. Townsend, "Tooth development standards for South Australia," Australian Dental Journal, vol. 47, no. 3, pp. 223-227, 2002.

[12] J. M. Morris and J. H. Park, "Correlation of dental maturity with skeletal maturity from radiographic assessment: a review," The Journal of Clinical Pediatric Dentistry, vol. 36, no. 3, pp. 309-314, 2012.

[13] A. Demirjian, H. Goldstein, and J. M. Tanner, "A new system of dental age assessment," Human Biology, vol. 45, pp. 211227, 1973.

[14] S. Krailassiri, N. Anuwongnukroh, and S. Dechkunakorn, "Relationships between dental calcification stages and skeletal maturity indicators in Thai individuals," The Angle Orthodontist, vol. 72, no. 2, pp. 155-166, 2002.

[15] A. Bagherpour, M. Pousti, and E. Adelianfar, "Hand skeletal maturity and its correlation with mandibular dental development," Journal of Clinical and Experimental Dentistry, vol. 6, no. 3, pp. e275-e279, 2014.

[16] V. Yadav, A. Loomba, and R. Autar, "A comparative evaluation of dental calcification stages and skeletal maturity indicators in North-Indian children," National Journal of Maxillofacial Surgery, vol. 8, no. 1, pp. 26-33, 2017.

[17] A. Ojha, M. A. Prasanth, V. Singh, T. Sihag, V. Bhati, and H. Tomar, "Assessment of correlation between dental calcification stages and skeletal maturity indicators," Journal of Forensic Dental Sciences, vol. 10, no. 3, pp. 132-136, 2018.

[18] M. Joshi, D. Rao, A. B. Shubha, S. Panwar, and S. Franklin, "A radiographic assessment of the correlation between the calcification stages of the mandibular second molar and the middle phalanx of the third finger of 9-16 years old children," Egyptian Journal of Forensic Sciences, vol. 8, no. 1, p. 35, 2018.

[19] R. M. Lecca-Morales and M. J. Carruitero, "Relationship between dental calcification and skeletal maturation in a Peruvian sample," Dental Press Journal of Orthodontics, vol. 22, no. 3, pp. 89-96, 2017.

[20] P. C. Motghare, A. S. Bedia, S. S. Degwekar, A. D. Indurkar, and S. Bedia, "Correlation of calcification of permanent mandibular canine, mandibular premolars, and permanent 
mandibular first and second molars with skeletal maturity in Indian population," Journal of Forensic Dental Sciences, vol. 8, no. 2, pp. 67-73, 2016.

[21] A. Rao, V. Palanisamy, R. Shenoy, and S. S. Baranya, "Correlation of dental age, skeletal age, and chronological age among children aged 9-14 years: a retrospective study," Journal of the Indian Society of Pedodontics and Preventive Dentistry, vol. 34, no. 4, pp. 310-314, 2016.

[22] H. O. Al-Balbeesi, N. W. Al-Nahas, L. F. Baidas, S. M. Bin Huraib, R.'a. Alhaidari, and G. Alwadai, "Correlation between skeletal maturation and developmental stages of canines and third molars among Saudi subjects," The Saudi Dental Journal, vol. 30, no. 1, pp. 74-84, 2018.

[23] M. V. Bittencourt, G. Cericato, A. Franco, R. Girão, A. P. B. Lima, and L. Paranhos, "Accuracy of dental development for estimating the pubertal growth spurt in comparison to skeletal development: a systematic review and meta-analysis," Dento Maxillo Facial Radiology, vol. 47, no. 4, p. 20170362, 2018.

[24] K. C. Grave and T. Brown, "Skeletal ossification and the adolescent growth spurt," American Journal of Orthodontics, vol. 69, no. 6, pp. 611-619, 1976.

[25] A. Björk and S. Helm, "Prediction of the age of maximum puberal growth in body height," The Angle Orthodontist, vol. 37, no. 2, pp. 134-143, 1967.

[26] L. S. Fishman, "Maturational patterns and prediction during adolescence," The Angle Orthodontist, vol. 57, no. 3, pp. 178193, 1987.

[27] S. Chertkow, "Tooth mineralization as an indicator of the pubertal growth spurt," American Journal of Orthodontics, vol. 77, no. 1, pp. 79-91, 1980.

[28] T. Uysal, Z. Sari, S. I. Ramoglu, and F. A. Basciftci, "Relationships between dental and skeletal maturity in Turkish subjects," The Angle Orthodontist, vol. 74, no. 5, pp. 657-664, 2004.

[29] S. Kumar, A. Singla, R. Sharma, M. S. Virdi, A. Anupam, and B. Mittal, "Skeletal maturation evaluation using mandibular second molar calcification stages," The Angle Orthodontist, vol. 82, no. 3, pp. 501-506, 2012.

[30] L. J. Lopes, T. de Oliveira Gamba, M. A. P. G. Visconti, G. M. B. Ambrosano, F. Haiter-Neto, and D. Q. Freitas, "Utility of panoramic radiography for identification of the pubertal growth period," American Journal of Orthodontics and Dentofacial Orthopedics, vol. 149, no. 4, pp. 509-515, 2016.

[31] S. Coutinho, P. H. Buschang, and F. Miranda, "Relationships between mandibular canine calcification stages and skeletal maturity," American Journal of Orthodontics and Dentofacial Orthopedics, vol. 104, no. 3, pp. 262-268, 1993.

[32] Y. Lü, "Relationships between mandibular canine calcification stages and skeletal maturity," Zhonghua Kou Qiang Yi Xue Za Zhi, vol. 34, no. 1, pp. 40-42, 1999.

[33] G. Perinetti, L. Contardo, P. Gabrieli, T. Baccetti, and R. di Lenarda, "Diagnostic performance of dental maturity for identification of skeletal maturation phase," European Journal of Orthodontics, vol. 34, no. 4, pp. 487-492, 2012.

[34] A. M. Sahin Sağlam, "The relationship between dental and skeletal maturity," Journal of Orofacial Orthopedics, vol. 63, no. 6, pp. 454-462, 2002.

[35] D. G. Kang, T. W. Kim, Y. J. Kim, S. H. Nam, and H. J. Kim, "Relationship between dental calcification stages and skeletal maturity indicators in Korean individual," The Journal of the
Korean Academy of Pedtatric Dentistry, vol. 35, no. 2, pp. 243-258, 2008.

[36] A. Singla, S. Mittal, A. Singla, M. Virdi, R. Sharma, and B. Mittal, "Co-relation between determination of skeletal maturation using cervical vertebrae and dental calcification stages," The Internet Journal of Forensic Science, vol. 4, no. 2, 2011.

[37] S. Chertkow and P. Fatti, "The relationship between tooth mineralization and early radiographic evidence of the ulnar sesamoid," The Angle Orthodontist, vol. 49, no. 4, pp. 282288, 1979.

[38] D. Jatti, Y. Kantaraj, R. Nagaraju, S. Janardhan, and S. Nataraj, "Age estimation by measuring open apices of lower erupted teeth in 12-16 years olds by radiographic evaluation," Journal of Forensic and Legal Medicine, vol. 20, no. 5, pp. 430-434, 2013.

[39] Y. N. Issa, A. S. Burhan, F. R. Nawaya, and L. G. Massouh, "Assessment of the pubertal growth period using the open apices of the lower teeth," The Journal of Contemporary Dental Practice, vol. 18, no. 1, pp. 16-22, 2017.

[40] R. Cameriere, L. Ferrante, D. de Angelis, F. Scarpino, and F. Galli, "The comparison between measurement of open apices of third molars and Demirjian stages to test chronological age of over 18 year olds in living subjects," International Journal of Legal Medicine, vol. 122, no. 6, pp. 493-497, 2008.

[41] A. Demirjian, P. H. Buschang, R. Tanguay, and D. K. Patterson, "Interrelationships among measures of somatic, skeletal, dental, and sexual maturity," American Journal of Orthodontics, vol. 88, no. 5, pp. 433-438, 1985.

[42] S. Surendran and E. Thomas, "Tooth mineralization stages as a diagnostic tool for assessment of skeletal maturity," American Journal of Orthodontics and Dentofacial Orthopedics, vol. 145, no. 1, pp. 7-14, 2014.

[43] G. Perinetti, G. H. Westphalen, M. Biasotto, S. Salgarello, and L. Contardo, "The diagnostic performance of dental maturity for identification of the circumpubertal growth phases: a meta-analysis," Progress in Orthodontics, vol. 14, no. 1, p. 8, 2013. 